\title{
Bronchopulmonary dysplasia: a new look at management
}

\author{
D P Southall, M P Samuels
}

Bronchopulmonary dysplasia is an unacceptable but, at present, seemingly unavoidable complication of neonatal intensive care. There are many theories as to why this disorder arises, including lung immaturity, barotrauma from positive airway pressure ventilation, oxygen toxicity, respiratory infections after intubation, and increased lung fluid. Definitions vary, but based on the physiological definition of oxygen dependency at 28 days of age, Boynton has estimated that in the USA 3100 infants are suffering from chronic lung disease at any given time. ${ }^{1}$ Based on similar calculations, there may be up to 730 in the UK. After initial hospital discharge, there is a high rate of readmission (up to $60 \%$ ) and subsequent death (up to $20 \%$ ). $^{2}$

Having been referred over 90 infants with severe bronchopulmonary dysplasia over the last three years, we have updated our management of infants both in hospital and at home. This paper aims to survey conventional treatment in combination with the presentation of new ideas, including the maintenance of 'normal' oxygenation and the use of negative pressure ventilation as a non-invasive respiratory support.

\section{Clinical management in hospital}

(1) DIFFERENTIAL DIAGNOSIS

Infants undergo the following investigations to exclude additional problems where management may be affected: an echocardiogram (for example, to exclude patent ductus arteriosus or anomalous pulmonary venous drainage), sweat test, nasociliary studies, immunoglobulins (including IgE). In selected cases ventilationperfusion scans may rarely confirm a localised lung defect.

\section{(2) PREVENTION OF HYPOXAEMIA}

Inadequate airway oxygenation, as reflected by arterial or transcutaneous measurements, will result in a greater tendency to develop pulmonary vascular hypertension and cyanotic episodes associated with a right to left arteriovenous intrapulmonary shunt. ${ }^{3}$ Such episodes may be induced by crying or handling, ${ }^{34}$ feeding, ${ }^{5}$ and infection. ${ }^{6}$ They are potentially dangerous and may result in a pulmonary vascular crisis (a major hypoxaemic episode) or sudden death. ${ }^{7}$

In addition to the acute and episodic development of a right to left intrapulmonary shunt, chronic intrapulmonary shunting from inadequate airway oxygenation may produce hypoxaemia over and above that directly due to alveolar hypoventilation. Such shunting may also lead to interstitial pulmonary oedema, simi- lar to that arising from high altitude exposure ${ }^{8}$ and may explain why diuretics are of value in some patients with bronchopulmonary dysplasia (see later). While we may use diuretics for established pulmonary hypertension and right heart failure, we would advocate the prevention of this complication. The presence of an accentuated pulmonary component of the second heart sound, right ventricular hypertrophy on electrocardiography or echocardiography, and cyanosis on crying or feeding indicate that airway oxygenation has been inadequate.

The persistent abnormalities in lung surfactant, which have been demonstrated in infants with bronchopulmonary dysplasia, ${ }^{9}$ may also result from underperfusion or hypoxia of the alveoli. Thus an adequate airway oxygen tension and adequate effective pulmonary blood flow (that is, without a shunt) may also be important in maintaining function of the alveolar type I and type II cells.

Inadequate oxygenation may also be one cause of the failure to thrive seen in patients with bronchopulmonary dysplasia. There is evidence that additional inspired oxygen may reverse poor weight gain ${ }^{10}$ and that weaning infants from additional inspired oxygen too early such that they sustain prolonged periods with arterial hypoxaemia (arterial oxygen saturation $\left(\mathrm{SaO}_{2}\right)<95 \%$ ) may divert energy from growth (J R Groothius; Ross Laboratories Special Conference on Bronchopulmonary Dysplasia, Washington DC, December 1989).

Non-invasive and continuous monitoring of oxygenation would ideally involve both accurate transcutaneous oxygen tension $\left(\mathrm{TcPO}_{2}\right)$ and $\mathrm{SaO}_{2}$ measurements. Fanconi has shown that pulse oximeters from different manufacturers have different responses, and that before clinical use in neonates they should be validated against arterial line samples measured using a co-oximeter which compensates for fetal haemoglobin. ${ }^{11}$ The Nellcor and Ohmeda pulse oximeters are the models most adequately validated in infants, ${ }^{11-13}$ although the Ohmeda is less adequate at detecting hyperoxaemia ${ }^{14}$ and may under-read the true $\mathrm{SaO}_{2}{ }^{15}$

In this age group $\mathrm{TcPO}_{2}$ is far less accurate at detecting airway hypoxia than pulse oximetry, in part because of changes in skin blood flow with increasing age. ${ }^{16}$ Moreover, the oxygen dissociation curve can be shifted to the right or left depending on 2,3-diphosphoglycerate and fetal haemoglobin concentrations, ${ }^{17}$ thus altering the relationship between arterial oxygen pressure $\left(\mathrm{PaO}_{2}\right)$ and $\mathrm{SaO}_{2}$. Although $\mathrm{TcPO}$ is useful as a trend measurement (see later), we find pulse oximetry a more accurate measure of 
arterial oxygenation and therefore more useful in the definitive evaluation of airway hypoxia.

Before ensuring adequate oxygenation for any infant it is essential to know what is normal at that age and gestation. ${ }^{18}$ Two recent investigations performed in our department are relevant. Overnight ( 12 hour) tape recordings of beat to beat $\mathrm{SaO}_{2}$ (using a Nellcor $\mathrm{N} 100$ pulse oximeter), breathing movements and electrocardiogram have been performed on healthy full term infants at the following ages: in the first month of life $(n=43)$, at around 6 weeks of age $(n=67)$, at around 3 months of age $(n=19)$, and around 6 months of age $(n=18)$. At 6 weeks of age, the median value for the baseline $\mathrm{SaO}_{2}$ during regular breathing, a state closely correlated with quiet sleep, was $99.8 \%$ (range 97.0 to $100 \%)$.

In a similar study on an unselected sample of 66 preterm infants at the time of discharge from special care, the median baseline $\mathrm{SaO}_{2}$ during regular pattern breathing was $99 \cdot 4 \%$. Moreover, 63 of the 66 subjects had baseline values above $95 \%$.

Thus most preterm and full term infants manifest baseline $\mathrm{SaO}_{2}$ values between 97 and $100 \%$. These values should therefore be considered as normal when providing additional inspired oxygen to compensate for airway hypoxia resulting from bronchopulmonary dysplasia. Because of the potential dangers of hyperoxaemia in the infant before term, the $\mathrm{SaO}_{2}$ while on additional inspired oxygen must not be permitted to remain at $100 \%$ for any length of time. Allowing for an error of $\pm 2 \%$ on the Nellcor pulse oximeter, ${ }^{12}$ we maintain $\mathrm{SaO}_{2}$ between 95 and $98 \%$ in patients with bronchopulmonary dysplasia.

When the inspired oxygen requirement is $40 \%$ or less maintenance of an adequate inspired oxygen pressure $\left(\mathrm{PO}_{2}\right)$ can be achieved by neonatal nasal cannulae (for example, De Vilbiss, Feltham, Middlesex). More than $40 \%$ inspired oxygen is provided using a headbox. However, retention of the nasal cannulae may minimise swings in oxygenation that result from disturbances to the headbox oxygen content. It is also important to be aware that handling and medical or nursing procedures, which result in hypoxaemia, ${ }^{4}$ may also interrupt the amount of oxygen supplied to the infant at a time when particularly needed. Constant non-invasive monitoring of oxygen concentrations may help prevent iatrogenic hypoxaemia: ${ }^{19} 20$ clinical detection based on cyanosis alone will detect only more severe disturbances. When a patient is demonstrating falls in $\mathrm{SaO}_{2} / \mathrm{PO}_{2}$ on feeding, we provide extra additional inspired oxygen before and during such events. This may mean temporarily increasing the inspired oxygen level from 40 to perhaps 70 or $80 \%$. Noxious procedures, such as the taking of blood or passage of nasogastric tubes, produce crying and may result in severe hypoxaemia. We always provide additional oxygen before such procedures and, as clinically appropriate, adequate local or systemic analgesia or sedation. If an infant is severely upset by a procedure, return to the previous requirements of additional inspired oxygen may take up to several hours.
An additional way of improving oxygenation involves the use of continuous or intermittent negative pressure ventilation. ${ }^{21}$ This is described below.

\section{(3) CARBON DIOXIDE RETENTION}

Some patients with bronchopulmonary dysplasia have few problems with carbon dioxide retention, suggesting that most of their disease process has selectively affected alveolar gas exchange. Some patients, however, have predominantly small airway disease, recognised by wheeze or evidence of air trapping. In any patient with bronchopulmonary dysplasia and a high arterial carbon dioxide pressure $\left(\mathrm{PaCO}_{2}\right)$ in the absence of severe oxygenation problems, one must ensure that upper airway obstruction, most commonly resulting from subglottic stenosis, is not present. Laryngeal injury, resulting from endotracheal intubation, has been reported to occur in up to $55 \%$ of intubated infants ${ }^{22}$ and may be clinically silent. Diagnosis may be achieved by carefully watching the infant's pattern of breathing when asleep, by listening over the larynx with a stethoscope and by tape recordings of inspiratory waveform pattern (inductance plethysmography), $\mathrm{SaO}_{2}$ and carbon dioxide pressure $\left(\mathrm{PCO}_{2}\right)$ concentrations during sleep. ${ }^{23}$ Ultimately, endoscopy may be indicated.

Lower airway obstruction may be partly relieved by corticosteroids, methylxanthines, nebulised $\beta$ agonists or anticholinergics, and occasionally by diuretics. We have also found continuous negative extrathoracic pressure (CNEP) to be of some value; perhaps by increasing the transthoracic pressure gradient, thereby improving airway patency during expiration and effectively replacing the auto positive end expiratory pressure (PEEP) or intrinsic PEEP caused by small airway closure at end expiration. ${ }^{24}$ One promising new treatment is the use of nebulised budesonide, a corticosteroid (Astra Pharmaceuticals). Unlike systemic corticosteroids ${ }^{25}$ (A Grant; Ross Laboratories Special Conference on Bronchopulmonary Dysplasia, Washington DC, December 1989) neither CNEP or nebulised budesonide have yet been subjected to randomised controlled trial.

\section{(4) NEGATIVE PRESSURE VENTILATION}

We use this treatment if more than $40 \%$ inspired oxygen is required to maintain $\mathrm{SaO}_{2}$ at 95 to $98 \%$ when quiet or asleep, if there is evidence of noticeable respiratory distress with failure to thrive, and to help in reducing the deterioration that occurs when some infants are weaned from systemic corticosteroids. It is also valuable during intercurrent respiratory infections, particularly in situations where respiratory failure is worsening and further respiratory support is indicated. Being non-invasive it may be used earlier than one would subject an infant to intubation ${ }^{21}$ and without the adverse haemodynamic effects produced by intermittent positive pressure ventilation (IPPV). Although positive airway pressure techniques increase 
ventilation, they increase pulmonary vascular resistances and reduce cardiac output and effective pulmonary blood flow. Thus the gains from improved ventilation may not be fully reflected by improvements in tissue oxygenation. Negative extrathoracic pressure improves ventilation and pulmonary perfusion. Negative pressure may be continuous (CNEP -6 to $-8 \mathrm{~cm} \mathrm{H}_{2} \mathrm{O}$ ) or intermittent (intermittent negative extrathoracic pressure of $-35 /-6$, rate $10-60 /$ minute). The latter is initiated when there is increasing carbon dioxide retention or the infant has become tired. CNEP may be given overnight only; the patient breathing unaided during the daytime.

\section{(5) AVOIDANCE OF ANAEMIA}

There are two reasons why anaemia should be avoided. Firstly the adverse effects of anaemia on the delivery of oxygen to tissues may impair optimal tissue growth, ${ }^{17}$ particularly in the lung. Secondly anaemia may increase the incidence of cyanotic episodes. ${ }^{26}$ Correction of anaemia has been shown to reduce the incidence of hypoxaemic episodes, ${ }^{26}$ reduce oxygen consumption, ${ }^{27}$ and decrease the incidence of apnoeic pauses and periodic breathing. ${ }^{28} 29 \mathrm{We}$ therefore aim to keep the haemoglobin concentration between 110 and $140 \mathrm{~g} / \mathrm{l}$. Regular iron and folic acid supplements are provided until the infant is on an adequate mixed diet. If the haemoglobin falls below $110 \mathrm{~g} / \mathrm{l}$ a blood transfusion is given.

\section{(6) DIURETICS}

Controlled trials have shown that diuretics may improve respiratory function in patients with bronchopulmonary dysplasia. ${ }^{30-32}$ We use a combination of frusemide $(1 \mathrm{mg} / \mathrm{kg} / \mathrm{dose}$ two to three times per day) and spironolactone (1-1.5 $\mathrm{mg} / \mathrm{kg}$ twice daily) if right heart failure is present or if there is radiological evidence of interstitial fluid with a persistent oxygenation defect. As described above, however, it should be possible to prevent pulmonary oedema and right heart failure by maintaining adequate airway oxygenation thus avoiding the need for diuretics. Frusemide may cause hypercalcuria and thus in infants with a high alkaline phosphatase activity or radiological evidence of rickets or nephrocalcinosis, chlorthiazide (10-20 mg/kg twice a day) is preferable.

\section{(7) SYSTEMIC CORTICOSTEROIDS}

Controlled trials have indicated earlier extubation with corticosteroids, although the durations of oxygen dependency and hospital stay may not be helped. ${ }^{33}{ }^{34}$ Where there is increasing carbon dioxide retention or inability to wean from IPPV we use a three to five day course of dexamethasone at full dosage $(0.25 \mathrm{mg} / \mathrm{kg}$ every 12 hours). If there is no initial improvement it is discontinued immediately. When an improvement has occurred it is tailed off over seven to 21 days. In those infants in whom deterioration occurs on stopping corticosteroids, we may use nebulised budesonide $(0.5-1.0 \mathrm{mg} 12$ hourly) or alternate day steroids.
We are cautious in commencing corticosteroids because of their predisposition to and suppression of signs from infection. In addition long term effects of these drugs on the development of the fibrous tissue matrix within the lung warrant further study. ${ }^{35} 36$

\section{(8) NUTRITION}

As overall body growth is likely to be accompanied by increased lung development, we aim to optimise energy input and utilisation providing $0.63 \mathrm{MJ} / \mathrm{kg} /$ day (150 kcal) by supplementing feeds with additional carbohydrate (for example, Polycose (Abbott), Polycal (Cow and Gate), and Maxijul (Scientific Hospital Supplies)) and fat (for example, Liquigen, Calogen, and Duocal (all Scientific Hospital Supplies)). In the infant with persistent respiratory distress, energy consumption may be reduced by minimising the work of breathing, as for example using negative pressure ventilation. ${ }^{21}$

As a compliant ribcage will impair gas exchange in the lung and result in persistent respiratory distress, we monitor for the development of osteopenia of prematurity. ${ }^{37}$ In addition to vitamin D supplements, we may also provide calcium and phosphate. Deficiency of the latter may also contribute to persistent respiratory distress from muscle weakness. The potential effects of diuretics and steroids on calcium metabolism also have to be considered (see above).

\section{(9) INFECTION AND ITS TREATMENT AND} PREVENTION

Intercurrent respiratory infection frequently begins as a viral infection. Respiratory syncytial virus may be a particular problem for preterm infants in neonatal units as well as the community, ${ }^{38}$ with staff sometimes acting as the transmitter of infections. ${ }^{39}$ What may simply be a cold or upper respiratory infection for the average baby can be devastating for a patient with bronchopulmonary dysplasia. It is therefore our policy to provide increased protection for all such patients. Parents and nursing or medical staff with an upper respiratory tract infection should rigidly avoid contact with such patients. In the most susceptible infants reverse barrier nursing may be provided. As soon as an upper respiratory tract infection is suspected, a nasopharyngeal aspirate should be taken for immunofluorescence in order to identify respiratory syncytial virus, parainfluenza, or adenovirus, for which it may be helpful to administer nebulised ribavirin. Adenovirus may be particularly problematic as bronchiolitis obliterans may make chronic lung changes irrepairable.

In the systemically ill infant (that is, with a fever, a leucocytosis, increased $C$ reactive protein, and additional changes on chest radiography) we will administer a minimum five day course of broad spectrum intravenous antibiotics.

There is some evidence that Ureaplasma urealyticum infection may increase the likelihood of chronic lung disease in preterm infants. ${ }^{40} \mathrm{We}$ consider administering a seven day course of 
erythromycin on an empirical basis in the presence of a fever, with or without respiratory symptoms after blood, endotracheal tube, throat, and urine cultures. In most instances, however, the cause of the fever is likely to be viral in origin and the results from serology may help identify the pathogen.

It is important to be aware of the potential danger of the less common pathogens such as monilia, particularly in the patient on corticosteroids. If there is a conjuctivitis, special swabs for chlamydia are taken and the infection treated with a minimum 10 day course of systemic erythromycin.

Early immunisation against pertussis is extremely important. This is begun at three months after delivery, whether or not the patient is in hospital.

\section{(10) MONITORING}

All of our patients with bronchopulmonary dysplasia are continuously monitored using a Nellcor pulse oximeter for assessment of baseline hypoxaemia and daily measurement of additional inspired oxygen requirement (see below). ${ }^{41}$ During intercurrent respiratory infections, transcutaneous carbon dioxide pressure $\mathrm{TcPCO}_{2}$ ) is monitored using a sensor heated to $42^{\circ} \mathrm{C}$ (Hewlett Packard/Draeger electrode) and changed every 12 hours. If there is any deterioration in $\mathrm{TcPCO}_{2}$ or in oxygenation, capillary gas samples can be taken for an analysis of $\mathrm{pH}, \mathrm{PCO}_{2}$, standard bicarbonate, and base excess.

The measurement of additional oxygen requirement is used to assess respiratory function on a daily basis. In non-intubated patients this procedure involves placing the patient's head in a headbox, switching off the nasal cannula oxygen supply, providing oxygen in the headbox, and placing an oxygen analyser (calibrated in air and $100 \%$ oxygen) next to the infant's nose. The level of inspired oxygen required to keep the $\mathrm{SaO}_{2}$ between 95 and $98 \%$ is assessed when the patient is quietly asleep. We expect to see oxygen requirements stablethat is, not changing by more than $0.25 \mathrm{1} / \mathrm{min}$ through the nasal cannulae, before discharge home is considered.

\section{Home management}

PREPARATION FOR HOME

Before discharge a planning meeting is held to which are invited key workers who have been, or will be, responsible for the care of the baby (see table 1). At this meeting the items listed in table 2 are discussed and channels of communication provided.

\section{HOME MONITORING}

Preterm infants are at increased risk of sudden, unexpected death (between $1 / 42$ and 1/200). ${ }^{42-46}$ Those with bronchopulmonary dysplasia are probably at greater risk, whether in hospital $^{7}$ or at home. ${ }^{47}$ Although these deaths may not be classified as sudden infant death syndrome, the mechanism being thought by some
Table 1 Key workers invited to discharge planning meeting

\begin{tabular}{ll}
\hline Unit/ward nurses & Hospital paediatric staff \\
Family practitioner & Health visitor \\
Clinical nurse specialist & Liaison health visitor \\
Social worker & Parents \\
\hline
\end{tabular}

Table 2 Items for discussion at discharge planning meeting

(1) Home oxygen supply: concentrators, cylinders

(2) Home $\mathrm{PO}_{2}$ monitor: instruction

(2) Training in resuscitation

(4) Training in respiratory support-for example, negative extrathoracic pressure

(5) Training in nasogastric tube feeding and changing

(6) Discussion of medications, immunisations

(7) Discussion of medification of: Fire department Electricity department

British Telecom (priority fault repair service) Insurance company (for building/equipment)

(8) Identification of lines of communication for medical/ equipment problems

(9) Discharge transport

(10) Respite care

(11) Financial help

12) Follow up:

Home visits (health visitor, clinical nurse specialist) Outpatient

to be different in infants with chronic lung disease, home monitoring is appropriate in this group of infants. ${ }^{48}$ Clinical recognition of hypoxaemia is poor; it may easily be undetected $^{5}$ (JR Groothius; Ross Laboratories Special Conference on Bronchopulmonary Dysplasia, Washington DC, 1989), and this may be the precursor for more major life threatening events. ${ }^{3}$ For the early detection of major cyanotic/apnoeic events, we use a $\mathrm{TcPO}_{2}$ monitor (Kontron 821S). The sensor for this instrument is heated to $43^{\circ} \mathrm{C}$ and its site changed every eight hours. ${ }^{49}$ Although skin $\mathrm{PO}_{2}$ measurements do not accurately measure $\mathrm{PaO}_{2}$, compared with $\mathrm{SaO}_{2}$ measurements from validated pulse oximetry, they are less prone to movement artefact, produce fewer false alarms and may be used continuously when the infant is discharged home. They are also able to identify falls in baseline skin $\mathrm{PO}_{2}$ indicative of arterial hypoxaemia, for example in the setting of an intercurrent respiratory infection. In 28 infants with bronchopulmonary dysplasia, seven had falls in baseline $\mathrm{PO}_{2}$, identified by the monitor, and later proved to be hypoxaemia by a validated pulse oximeter in hospital. ${ }^{49}$ Three subsequently needed respiratory support because of progressive respiratory failure. Parents rapidly become aware of changes in baseline $\mathrm{PO}_{2}$ and respond by arranging medical assessment of the infant's clinical state and confirmation or otherwise of arterial hypoxaemia by pulse oximetry. The monitor is also an important tool for the surveillance of additional inspired oxygen supply at home (see below).

DOMICILIARY OXYGEN TREATMENT

To administer oxygen, a home based and a mobile supply both need to be available. The first is provided by an oxygen concentrator which is prescribable by the family practitioner. ${ }^{50}$ These are provided by either De Vilbiss, Omnicare, or Rimer-Alco (depending 
on area), who will visit the home and install the most appropriate system to suit the parents' living conditions. The cost and convenience of a concentrator makes this much more suitable than large cylinders for long term oxygen supply, even taking electricity costs into account. Cylinders are heavy, run out, have a delivery charge of $£ 23$, and ultimately are more expensive. When an infant requires $0.51 / \mathrm{min}$, the cost per annum of a concentrator is $£ 1030$, compared with £3705-4901 for cylinders, depending on whether one or two deliveries per week are needed. Thus we invariably recommend a concentrator to be installed in the home. Parents may be reimbursed from the Family Practitioner Committee the cost of electricity used as this is metered and read by the concentrator supplier.

Secondly, small portable oxygen cylinders (usually size $\mathrm{C}$ or $\mathrm{D}, \mathrm{BOC}$ ), are required for when the baby is away from home, either in the car, out in the pram or at relatives' or friends' houses. They may allow mobility for up to 28 hours (see table 3). After negotiation BOC cylinders can usually be replaced when empty by the hospital pharmacy, but if used frequently this may be impractical. Small pin indexed cylinders are available ( $£ 494$, SOS, Richmond, Surrey) which allow refilling at home from a single large cylinder. This is ultimately more convenient for parents, but involves a more expensive initial outlay for the hospital. Oxygen concentrators and small cylinders in most instances will need to be equipped with low flow meters. These are not prescribable by the family practitioner, so must be provided by the hospital and fitted by a qualified technician. De Vilbiss, however, supply them with their oxygen concentrator (for $£ 150$, payable by the hospital) and Omnicare may soon follow. Stocks of low flow meters are not large so one should allow ample time for ordering before discharge home.

We have found it preferable to supply oxygen through nasal cannulae as described earlier. Although lower flows can be used with a pernasal pharyngeal catheter, partial occlusion of a nostril and an increase in nasopharyngeal secretions may be a disadvantage of this technique. For emergency use the parents may also be provided with an Ambu bag and face mask of a size suitable for the baby.

Supervision of home oxygen treatment requires regular visits by a specialist nurse who can monitor the infant's oxygen requirement with a headbox and oxygen analyser (as described above), as well as give advice about the clinical aspects of adequate oxygenation. At the time of the visit the nurse will also measure, using a pulse oximeter, the $\mathrm{SaO}_{2}$ of the baby

Table 3 Mobility using a size $C$ oxygen cylinder

\begin{tabular}{ll}
\hline Flow rate (l/min) & $\begin{array}{l}\text { Hours of oxygen } \\
\text { provided (approx) }\end{array}$ \\
\hline 0.1 & 28 \\
0.2 & 14 \\
0.3 & 9 \\
0.4 & 7 \\
0.5 & 6 \\
0.6 & 4.5 \\
\hline
\end{tabular}

while quiet and asleep and compare this with the $\mathrm{TcPO}_{2}$ monitor values. As mentioned above, the $\mathrm{SaO}_{2}$ of normal babies at home is between 97 and $100 \%$ when asleep. The aim of additional inspired oxygen should therefore be to keep values in this range. After allowing for $\mathrm{a} \pm 2 \%$ error on the pulse oximeter (Nellcor), $\mathrm{SaO}_{2}$ should thus be kept $97-98 \%$ when asleep. As lung disease resolves, an overnight tape recording of $\mathrm{SaO}_{2}$, breathing movements, and electrocardiography may guide the reduction in inspired oxygen concentrations. ${ }^{23}$ Short term measurements of oxygen saturation (for example, for 20 minutes) may inadequately reflect the variations that may occur in such infants (JR Groothius; Ross Laboratories Special Conference on Bronchopulmonary Dysplasia, Washington DC, December 1989).

Parents are often worried that nasal cannulae may become displaced during their sleep. Use of a $\mathrm{TcPO}_{2}$ monitor provides early warning that this has happened. Parents are also worried about electricity cuts. A new three pin plug (B and R Electrical Products, Harlow) that fits any household socket will alarm if this happens thus allowing parents temporarily to supply oxygen from a cylinder. Because of the high dependency of these infants on electricity we notify the local electricity board before their discharge from hospital.

\section{AVOIDANCE OF INFECTION}

All respiratory tract infections are potentially dangerous or lethal to the patient with bronchopulmonary dysplasia. It is therefore essential that, as far as possible, such infections are avoided. ${ }^{51}$ We therefore do not advise parents to take their infants to the health visitor clinics, preferring the health visitor to visit the patient. Most 'well-baby' clinics, also accommodate preschool children, many of whom carry respiratory infections, especially in the winter months. It is also important that the health visitor herself does not visit a baby with bronchopulmonary dysplasia if she has a respiratory infection. It is impossible to separate older siblings from infants with bronchopulmonary dysplasia, but if they do contract respiratory infections, it is probably best for them temporarily to minimise their contact and handling of the baby. Parental and sibling contact cannot be prevented, but any visitors to the house should not go near the baby if they are suffering from a respiratory infection. Similarly, visits to waiting rooms at doctors' surgeries are to be avoided because of the risk of cross infection. Once again, we request the general practitioner to visit the patient at home in this situation.

Because of the potential danger of pertussis infection in these infants ${ }^{52}$ we ensure that infants and their siblings complete their immunisations as soon as possible. There are few contraindications to pertussis immunisation (see Department of Health guidelines ${ }^{53}$ ) and yet such an infection could be fatal in a baby with bronchopulmonary dysplasia.

It is probably wise to cover respiratory infections with an oral antibiotic, such as amoxycillin, cefaclor, or erythromycin, particularly if 
there is a fever. All parents are given instruction in the accurate measurement of axillary temperature and taught how to observe an increase in chest wall recession, a useful sign of respiratory distress (C J Morley et al, personal communication).

Often the baby will manifest low $\mathrm{TcPO}_{2}$ values during an intercurrent infection or immediately after immunisation. These changes are due to either arterial hypoxaemia or reductions in skin blood flow, reflecting the presence of a non-specific illness. We suggest that whenever low $\mathrm{TcPO}_{2}$ values are encountered, they are checked immediately against a pulse oximeter in order to be sure that the infant does not require additional inspired oxygen and/or admission to hospital. In the meantime parents are advised temporarily to increase the inspired oxygen through the nasal cannulas.

\section{NUTRITION}

Sometimes it is necessary for feeds to be partly or wholly given by nasogastric tube at home. After appropriate training many parents become adept at passing a nasogastric tube and most would be able to feed their baby using this method. It may also be necessary for milk to have carbohydrate and/or fat supplements (as described earlier). We continue folic acid, iron, and multivitamin preparations until the infant has been weaned onto a mixed diet.

\section{RESPIRATORY SUPPORT}

It has sometimes been possible to discharge the infant while still receiving negative extrathoracic pressure respiratory support and for this to be provided at home. In patients who are dependent on this only during the overnight period, we have found that the risks of remaining in hospital outweigh the difficulties of applying this at home. The application of CNEP by parents can be readily taught, but of course, parents need regular supervision with immediate access to the hospital.

\section{EMOTIONAL SUPPORT OF THE PARENTS}

AND THE BABY

Infants who have severe chronic lung disease and have had prolonged intensive care will be a continual source of anxiety for both parents. It is important that the information they are given is honest, consistent, and regularly updated. This may be difficult when working on a busy unit. Thus the help of other counsellors and therapists may be particularly valuable in providing support. Lines of communication should always be available, and staff should be prepared to advise on more mundane needs such as financial and organisational problems.

\section{PSYCHOMOTOR DEVELOPMENT}

It is important that infants with bronchopulmonary dysplasia are given extra exercises and stimulation. Having had protracted neonatal intensive care, their development will more likely be hindered. Parents can be shown by physiotherapists how to stimulate their child appropriately for optimal development. In addition, the consultation of a speech therapist may help prevent the development of feeding difficulties. Once again it is important that any therapist or member of the Portage scheme who visits the infant at home does not do so if they have a respiratory infection.

\section{TRAINING IN CARDIOPULMONARY}

\section{RESUSCITATION}

Provided that airway oxygenation is adequately maintained, cyanotic episodes should not be a problem in these patients. Nevertheless, all parents should be able to provide bag and mask ventilation with $100 \%$ oxygen and external cardiac massage. This is taught to our parents by clinical nurse specialists with the help of a Resusci Baby (Laerdal Medical), video, and resuscitation manual (the latter available on request). We ask British Telecom to provide for priority repair in the event of faults developing with the home telephone. We also alert the local casualty department and ambulance station concerning the possibility that such an infant will require emergency attention.

\section{Conclusions}

There are many new ways in which one can help the infant with bronchopulmonary dysplasia. Most important of these concern the adequate management of airway oxygenation, the monitoring of skin oxygen levels, the avoidance of infection, and the provision of an adequate diet.

We would like to thank the nurses on our intensive care and children's wards for their help in caring so well for these patients. We are extremely grateful to Ms C Angel, Mrs K Jones, Ms J Noyes, Dr C Poets, Dr J Raine, and Dr A Spencer for their valuable ideas and criticisms and Ms B Cronin and Mrs J Lang for typing the manuscript. Dr Samuels is supported by CP Holdings.

1 Boynton BR. The epidemiology of bronchopulmonary dysplasia. In: Merritt TA, Northway WH, Boynton BR, eds. Bronchopulmonary Dysplasia. Boston: Blackwell Scientific Bronchopulmonary Dysplasia.

2 Shankaran S, Szego E, Eizert D, Siegel P. Severe bronchopulmonary dysplasia - predictors of survival and outcome. Chest 1984;86:607-10.

3 Southall DP, Samuels MP, Talbert DG. Recurrent cyanotic episodes with severe arterial hypoxaemia and intrapulmonary shunting: a mechanism for sudden death. Arch Dis Child 1990;65:953-61.

4 Long JG, Philip AGS, Lucey JF. Excessive handling as a cause of hypoxemia. Pediatrics 1980;65:203-7.

5 Garg M, Kurzner SI, Bautista DB, Keens TG. Clinically unsuspected hypoxia during sleep and feeding in infants with bronchopulmonary dysplasia. Pediatrics 1988;81: $635-42$.

6 Southall DP, Thomas M, Gurney A, Lambert HP. Prolonged expiratory apnoea and respiratory tract infections in infancy. Early Hum Dev 1988;17:91.

7 Abman SH, Burchell MF, Schaffer MS, Rosenberg AA. Late sudden unexpected deaths in hospitalised infants with sudden unexped deaths in hospitalised infants with bronch

8 Scoggin CH, Hyers TM, Reeves JT, Grover RF. High altitude pulmonary edema in the children and young adults of Leadville, Colorado. N Engl f Med 1977;297:1269-72.

9 Clement A, Masliah J, Housset B, et al. Decreased phosphatidyl choline content in bronchoalveolar lavage fluids of tidyl choline content in bronchoalveolar lavage fluids of
children with bronchopulmonary dysplasia. A preliminary children with bronchopulmonary dysplasia. A

10 Groothuis JR, Rosenberg AA. Home oxygen promotes weight gain in infants with bronchopulmonary dysplasia. weight gain in infants with bronch

11 Fanconi S. Pulse oximetry for hypoxaemia: a warning to users and manufacturers. Intensive Care Medicine 1989;15:540-2. 12 Southall DP, Bignall S, Stebbens VA, Alexander JR, Rivers RPA, Lissauer T. Pulse oximeter and transcutaneous arte- 
rial oxygen measurements in neonatal and paediatric intensive care. Arch Dis Child 1987;62:882-8.

13 Hay WW, Brockway JM, Eyzaguirre M. Neonatal pulse oximetry: accuracy and reliability. Pediatrics 1989;83: 717-22.

14 Bucher H-U, Fanconi S, Baeckert P, Duc G. Hyperoxemia in newborn infants: detection by pulse oximetry. Pediatrics 1989;84:226-30.

15 Nickerson BG, Sarkisian C, Tremper K. Bias and precision of pulse oximeters and arterial oximeters. Chest 1988;93: 515-7.

16 Hamilton PA, Whitehead MD, Reynolds EOR. Underestimation of arterial oxygen tension by transcutaneous electrode with increasing age in infants. Arch Dis Child 1985; 60:1162-5.

17 Comroe JH. Physiology of respiration. An introductory text. Chicago: Year Book Medical Publishers, 1974.

18 Stebbens VA, Alexander J, Southall DP. Oxygen saturation and breathing movement patterns in infants born before term. Pediatr Pulmonol 1989;7:281.

19 Lucey JF. Clinical uses of transcutaneous oxygen monitoring. Adv Pediatr 1981;28:27-56.

20 Peabody JL, Gregory GA, Willis MM, Philip AGS, Lucey JF. Failure of conventional monitoring to detect apnea resulting in hypoxemia. Birth Defects 1979;15:275-84.

21 Samuels MP, Southall DP. Negative extrathoracic pressure in treatment of respiratory failure in infa

22 Pashley NRT, Fan LI intubation in the neonate. In: Bancalari E Stocker JT, eds. . Bronchopulmonary dysplasia. Washington DC: Hemisphere Publishing Corporation, 1988:211-9.

23 Abraham NG, Stebbens VA, Samuels MP, Southall DP. Investigation of cyanotic/apneic episodes and sleep related upper airway obstruction by long term non-invasive

24 Smith TC, Marini JJ. Impact of PEEP on lung mechanics and work of breathing in severe airflow obstruction. $\mathcal{F} A p p l$ Physiol 1988;65:1488-99.

25 Stenmark KR. Steroids. In: Bancalari E, Stocker JT, eds. Bronchopulmonary dysplasia. Washington DC: Hemisphere Publishing Corporation, 1988:356-65.

26 Holowach J, Thurston DL. Breath-holding spells and anemia. N Engl f Med 1963;268:21-3.

27 Alverson DC, Isken VH, Cohen RS. Effect of booster blood transfusions on oxygen utilization in infants with bronchopulmonary dysplasia. I Pediatr 1988;113:722-6.

28 De Maio JG, Harris MC, Deuber C, Spitzer AR. Effect of blood transfusion on apnea frequency in growing premature infants. I Pediatr 1989;114:1039-41.

29 Joshi A, Gerhardt T, Shandloff P, Bancalari E. Blood transfusion effect on the respiratory pattern of preterm infants. fusion effect on the respiration $1987 ; 80: 79-84$
Pediatrics

30 Albersheim SG, Solimano AJ, Sharma AK, et al. Randomised double-blind, controlled trial of long term diuretic therapy for bronchopulmonary dysplasia. $\mathcal{F}$ Pediatr 1989;115: 615-20.

31 Engelhardt B, Blalock WA, Donlevy S, Rush MG, Hazinski JA. Effect of spironolactone-hydrochlorothiazide on lung function in infants with chronic bronchopulmonary dysplasia. F Pediatr 1989;114:619-24.

32 Rush MG, Engelhardt B, Donlevy S, Hazinski TA. Doubleblind placebo-controlled trial of alternate day frusemide therapy in infants with chronic BPD. Pediatr Res 1989;25: 308A.

See related papers on p 1076 and p 1082
33 Cummings JJ, D'Eugenio DB, Gross SJ. A controlled trial of dexamethasone in preterm infants at high risk for bronchopulmonary dysplasia. N Engl f Med 1989;320:1505-10.

34 Harkavy KL, Scanlon JW, Chowdhry PK, Grylack LJ. Dexamethasone therapy for chronic lung disease in trial. F Pediatr 1989;115:979-83.

35 Massaro D, Teich N, Maxwell S, Massaro D, Whitney P. Postnatal development of alveoli. Regulation and evidence for a critical period in rats. I Clin Invest 1985;16: for a critical

36 Beck JC, Mitzner W, Johnson JWC, et al. Betamethasone and the rhesus fetus: effect on lung morphometry and conand the rhesus fetus: effect on lung morphometr.

37 Niermeyer $\mathrm{S}$. Nutritional and metabolic problems in infants with bronchopulmonary dysplasia. In: Bancalari E, Stocker with bronchopulmonary dysplasia. In: Bancalari E, Stocker JT, eds. Bronchopulmonary dysplasia. Washingto

38 Groothuis JR, Gutierrez KM, Lauer BA. Respiratory syncytial virus infection in children with bronchopulmonary dysplasia. Pediatrics 1988;82:199-203.

39 Hall CB, Kopelman AE, Douglas Jr RG, Geiman JM, Meagher MP. Neonatal respiratory syncytial virus infections. N Engl f Med 1979;300:393-6.

40 Holtzman RB, Hageman JR, Yogev R. Role of Ureaplasma urealyticum in bronchopulmonary dysplasia. $\mathcal{F}$ Pediatr 1989;114:1061-3.

41 Samuels MP, Southall DP. Oxygen monitoring in paediatrics. Intensive Care World 1989;6:140-3.

42 Wariyar U, Richmond S, Hey E. Pregnancy outcome at 24-31 weeks' gestation: neonatal survivors. Arch Dis Child 1989;64:678-86.

43 Yardley J, Wailoo MP, Harman M. Postperinatal mortality among infants discharged from special care units. $\mathrm{BrMed} F$ among infants disch

44 Yu VYH, Watkins A, Bajuk B. Neonatal and postneonatal mortality in very low birthweight infants. Arch Dis Child mortality in very

45 Sells CJ, Neff TE, Bennett FC, Robinson NM. Mortality in infants discharged from a neonatal intensive care unit. Am f Dis Child 1983;137:44-7.

46 Kulkarni P, Hall RT, Rhodes PG, Sheehan MB. Postneonatal infant mortality in infants admitted to a neonatal intensive care unit. Pediatrics 1978;62:178-83.

47 Werthammer J, Brown ER, Neff RK, Taeusch HW. Sudden infant death syndrome in infants with bronchopulmonary dysplasia. Pediatrics 1982;69:301-4.

48 National Institutes of Health Consensus Development Conference Statement. Infantile apnea and home monitoring. Bethesda MD: US Department of Health and Human Services, 1987. (NIH Publication No. 87-290S.)

49 Samuels MP, Levene P, Southall D. Home monitoring of transcutaneous $\mathrm{PO}_{2}$ in the management of infants at transcutaneous $\mathrm{PO}_{2}$ in the management of infants at
increased risk of sudden death. Pediatr Pulmonol 1989;7: 280.

50 Bardsley $\mathrm{P}$, Howard P. Oxygen concentrators in the home. $\mathrm{Br}$ Med F 1988;297:1486-7.

51 Southall DP, Samuels MP. Respiratory infections, hypoxaemic episodes and sudden infant deaths-possible pathways in prevention? Maternal and Child Health 1989; 14:210-7

52 Southall DP, Thomas MG, Lambert HP. Severe hypoxaemia in pertussis. Arch Dis Child 1988;63:598-605.

53 Department of Health. Immunisation against infectious disease. London: DHSS, 1988:13-8. 